\title{
Beauty apps dan Budaya Makeover Digital di Kalangan Perempuan
}

\author{
Luri Renaningtyas \\ Dosen Desain Komunikasi Visual \\ Fakultas Seni dan Desain Universitas Kristen Petra \\ cocolatos@petra.ac.id
}

\begin{abstract}
Beauty apps provide easiness to those young women who seek beauty in daily basis without any make up nor do beauty treatments, these apps have the ability to enhance ones jaw line to look thinner without plastic surgery. They magically revise the overall look of ones selfie photo. After take selfie user especially woman can edit the photo by applying effects within the apps to enhance skin color, thinify the face, add makeup or even stretch the neck to look longer. The photo shows distinctly different look from what it actually represents in the real life. Prior to the previous research underlining woman's position over the man, woman can be the subject as well as man to make decisions when editing the photo using beauty apps. Feeling empowered, freed, facilitated by the apps, more and more women utilize them. They keen on doing this so called digital makeover on their photo before posting them on social media so rapidly that somehow it becomes a cultural activity. Therefore on this setting, this research is established as an explanation of a question of whether beauty is practiced by women through beauty apps. It is also provides description on how that practice leads to the women's way of seeing on beauty. It is qualitatively analyzed under the theory of media and feminism, enrich with technoculture discourse as well as philosophy of photography.
\end{abstract}

Keywords: beauty apps, digital makeover culture, selfie, beauty, media, woman.

Relevance to Visual Communication Design Practice: The research describes the condition that urge the phenomenon happens on the society this day. When technology is used on daily basis, it is considered as a grand design that is able to change the way of seeing and the way of thinking about everything within the cultural practice. This design-the beauty apps suggests the subculture of digital makeover on the society nowadays.

\section{PENDAHULUAN}

Kecantikan bisa diperoleh perempuan mana saja, di mana pun dan kapan pun. Peluang untuk menjadi cantik semakin besar dengan adanya aplikasi kecantikan (beauty apps). Untuk menjadi cantik, modal yang diperlukan hanyalah smartphone dan koneksi internet. Seiring dengan kemajuan TIK, smartphone bukan lagi merupakan barang mewah, sehingga semakin banyak penggunanya. Aplikasi kecantikan seperti Camera 360, Beauty Plus, atau Photo Wonder menjadi populer di kalangan perempuan sebagai pengguna utama aplikasi tersebut. Beauty apps membuat foto selfie menjadi cantik secara instan. Para penggunanya dapat mengambil foto diri dengan kamera Selfie yang dilengkapi filter cantik, kemudian secara otomatis foto selfie dapat terlihat cantik, foto tersebut diunggah ke sosial media seperti Instagram atau Facebook. Selain itu dengan Beautify mereka dapat memilih dan mengatur warna kulit pada foto selfie agar menjadi lebih putih, lebih halus, menambahkan riasan, mengubah bentuk rahang menjadi lebih tirus bahkan memanjangkan anggota tubuh seperti kaki dan leher. 


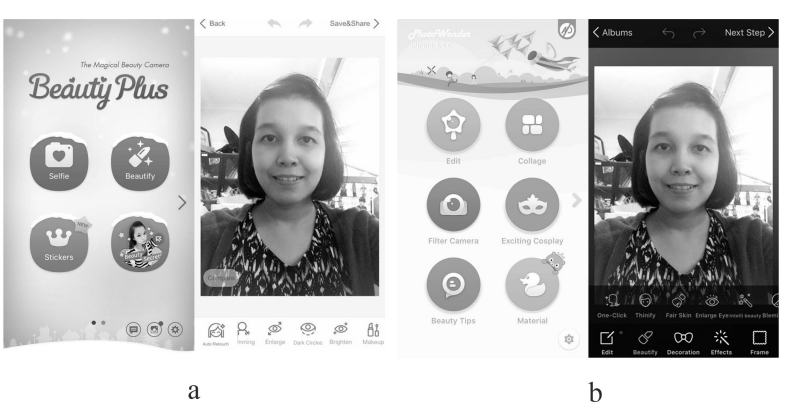

Gambar 1 antarmuka Beauty Plus (a) dan Photo Wonder (b). Kedua aplikasi di atas memiliki efek Beautify, menambahkan make-up, memperpanjang kaki atau leher, memperbesar mata dan meniruskan wajah. Sumber: dok. Luri Renaningtyas

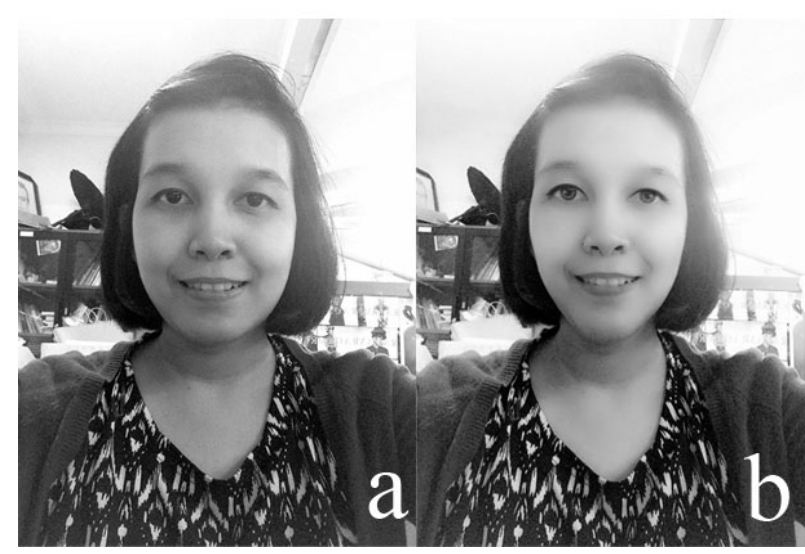

Gambar 2 Foto Selfie asli tanpa sunting (a). Foto selfie hasil sunting aplikasi Photo Wonder. Mengaplikasikan efek Fair Skin, Thinify, Make-up, Shape Leg untuk memperpanjang leher dan Enlarge Eye (b).

Sumber: dok. Luri Renaningtyas

Berdasarkan dari pengamatan dalam penelitian sebelumnya yang dilakukan terhadap perempuan yang menggunakan beauty apps Camera $360^{\mathrm{i}}$, pria berperan sebagai subyek, menentukan dan menilai penampilan perempuan sebagai obyek tontonannya, sekarang dengan adanya beauty apps posisinya telah bergeser, karena perempuan ternyata juga dapat berperan sebagai subyek yang 'berkuasa'. Perempuan bebas melakukan makeover dirinya, misalnya pada saat memilih efek atau mengaplikasikan filter, mengatur besar kecilnya ukuran mata, panjang pendeknya leher atau kaki, semuanya bergantung pada seleranya terhadap kecantikan dan fitur yang ada pada apps tersebut. Namun hasil makeover ini hanya sebatas di dalam foto, bersifat digital dan tidak berdampak apapun secara fisik, sehingga tampilan cantik yang dihasilkan tidak sama dengan yang aslinya di dunia nyata. Dikarenakan interaksi antara perempuan dan beauty apps sangat mudah dan instan, maka semakin banyak perempuan menggunakan aplikasi tersebut. Berdasarkan dari pengamatan terhadap fenomena ini, maka pertanyaan penelitiannya adalah seperti apa kecantikan dalam budaya makeover digital dipraktekkan melalui beauty apps di kalangan perempuan? Serta bagaimana budaya tersebut dapat berdampak pada perempuan dalam memaknai kecantikan dirinya? Peneliti mengamati interaksi antara pengguna (perempuan) dengan beauty appsperempuan di sini sebagai pusat penelitian diposisikan di antara penonton dalam budaya digital, sehingga secara keseluruhan mampu menjawab pertanyaan di atas, analisis dilakukan dengan teori media dan perempuan, didukung dengan diskursus teknologi dan budaya serta filosofi fotografi.

\section{LANDASAN TEORITIS}

Penelitian ini menggunakan teori media dan feminisme sebagai teori utama yang diperkuat dengan diskursus budaya dan teknologi serta filosofi fotografi. Dalam media dan feminise beauty apps dipandang sebagai sebuah media baru, media yang melibatkan interaksi penggunanya yaitu perempuan. Hal tersebut kemudian dikaitkan 
dengan konsep patriarki yang membahas tentang male gaze dan female gaze. Melalui media, perempuan diobyektifikasi oleh pria, perempuan sebagai obyek tontonan pria, namun karena adanya media baru posisi perempuan berubah menjadi subyek. Diskurus teknologi mendeskripsikan kondisi masyarakat digital yang hidup berdampingan dengan teknologi, menitik beratkan pada fenomena makeover digital pada perempuan dan kecantikan, sedangkan filosofi fotografi menjelaskan peranan foto sebagai bentuk representasi dari kecantikan hasil dari sebuah konstruksi sosial. Teori-teori di atas saling berkaitan dalam mendeskripsikan seperti apa budaya makeover digital yang dipraktekkan melalui beauty apps di kalangan perempuan dan bagaimana budaya tersebut berdampak pada perempuan dalam memaknai kecantikannya.

\section{METODE}

Penelitian dilakukan secara kualitatif dengan mengamati fenomena penggunaan beauty apps di kalangan perempuan, bagaimana perilaku mereka ketika berinteraksi dengan apps tersebut. Sebagian data pengamatan telah didapatkan dari penelitian sebelumnya tentang konstruksi kecantikan perempuan dengan aplikasi Camera 360. Perempuan adalah pusat dari penelitian dengan posisinya di antara penonton dalam budaya digital. Secara keseluruhan penelitian ini mendeskripsikan seperti apa budaya makeover digital yang dipraktekkan melalui beauty apps di kalangan perempuan dan bagaimana budaya tersebut memberikan dampak bagi perempuan dalam memaknai kecantikannya? Deskripsi disusun berdasarkan teori media dan perempuan, didukung dengan teori diskursus teknologi dan budaya serta filosofi fotografi.

Dari penelitian sebelumnya dengan studi kasus Camera360 peneliti telah mempunyai gambaran seperti apa dan bagaimana kecenderungan interaksi atau perilaku perempuan usia 17-24 tahun di Jakarta, Bandung dan Surabaya pada saat mengedit fotonya menggunakan apps tersebut. Peneliti juga melakukan observasi terhadap beauty apps lainnya seperti Beauty Plus dan Photo Wonder. Dalam penelitian ini data-data yang diperoleh digunakan sebagai dasar untuk menjelaskan fenomena dan permasalahan di atas ke ranah yang lebih luas yaitu kecantikan dalam budaya makeover digital yang dipraktekkan melalui beauty apps di kalangan perempuan dan dampaknya bagi perempuan dalam memaknai kecantikannya.

Data dari penelitian sebelumnya tentang kecenderungan perilaku perempuan dalam menggunakan aplikasi Camera 360 dan data observasi penggunaan beauty apps lainnya seperti Beauty plus dan Photo Wonder dianalisis dengan menggunakan teori Media dan Feminisme. Analisis tersebut didukung oleh diskursus teknologi dan filososfi fotografi. Semua dikaitkan dengan konsep kecantikan dalam praktek budaya digital untuk mendeskripsikan budaya makeover digital dan bahwa budaya tersebut dapat berdampak bagi perempuan dalam memaknai kecantikan dirinya. Teori media dan feminisme menitikberatkan pada bagaimana perempuan dikonstruksi dalam industri media yang dilihat dari kacamata sosiologi. Teori yang digunakan dari hasil pemikiran Widjajanti dapat mendeskripsikan bahwa teknologi dan media saling berkaitan dalam mengkonstruksi perempuan, yaitu 
feminitas dalam tontonan ${ }^{\text {ii }}$. Pembahasan Widjajanti didukung oleh Idi dan Bachruddin yang mendeskripsikan perempuan sebagai subyek yang aktif bukan lagi obyek pasif dari male gaze. Beauty apps adalah media baru yang mampu mengubah ritual dan cara pandang perempuan terhadap konsep kecantikan. Sebelumnya media didominasi oleh televisi yang bersifat pasif, namun dengan adanya media interaktif seperti beauty apps perempuan sebagai konsumen dapat aktif berinteraksi dengannya sehingga timbul perilaku baru. Pembahasan Yasraf tentang karakteristik masyarakat tontonan juga mempertajam deskripsi budaya digital dan kondisi masyarakatnya yang berdasar pada premis 'form follows fun' iii. Foto hasil suntingan beauty apps sebagai representasi cantik di dunia nyata yang menciptakan ritual dan cara pandang baru perempuan terhadap konsep kecantikan, ditarik kembali ke pengertian ontologisnya melalui uraian Lier yang mengacu pada Roland Barthes. Foto mengimplikasikan keakuratan dalam merepresentasi subyeknya di dunia nyata, sementara kecantikan yang ditampilkan di foto tidak sama dengan kecantikan fisiknya secara realitas. Foto hasil suntingan beauty apps juga dikritik karena kehilangan singularitasnya ${ }^{\text {iv }}$, ketika makeover digital semakin membudaya, semakin banyak perempuan menyunting fotonya menggunakan beauty apps dengan efek atau fitur yang sama.

\section{PEMBAHASAN}

\section{Budaya makeover digital}

Bagi kaum perempuan kecantikan adalah suatu keharusan, mereka berusaha sedemikian rupa untuk terlihat cantik, di antaranya dengan melakukan perawatan, memperbaiki penampilan di salon, dsb. Bahkan ketika perempuan dianggap tidak cantik, ia rela melakukan permak wajah dengan biaya yang tidak sedikit, misalnya di Korea operasi blepharoplasty (double eyelid surgery) untuk mengubah lipatan kelopak mata agar mata terkesan lebih besar dan $V$ line jaw reduction untuk mengubah bentuk rahang yang besar menjadi lebih kecil menyerupai bentuk huruf ' $V$.' Tampil cantik berarti juga lebih diterima di masyarakat, cantik selalu berkaitan dengan apa yang terlihat secara fisik, hal ini juga berlaku di Indonesia. Diawali dengan selebriti yang selalu terlihat cantik dan ideal, perempuan menjadikan selebriti sebagai role model-nya. Sebelumnya, kecantikan yang seolah hanya dimiliki oleh para selebriti dan orang-orang kaya, kini dengan adanya teknologi makeover digital, cantik menjadi hal yang lebih demokratis. Siapa pun dapat menjadi cantik tanpa harus mengeluarkan banyak biaya.

Teknologi makeover digital sebenarnya sudah lama ada, seperti software Photoshop yang populer digunakan dalam industri showbiz untuk menyunting foto tubuh para selebriti menjadi langsing dan memermak foto wajah mereka menjadi halus tanpa cacat. Sekarang, dengan beauty apps di smartphone seperti Camera 360, Beauty Plus, Photo Wonder, Make Up Genius, dsb, setiap perempuan dapat dengan mudah mempercantik tampilan foto selfie-nya. Hanya dengan menyentuh layar smartphone pengguna beauty apps dapat mengaplikasikan efek dan fitur tertentu ke foto. Misalnya Whiten untuk memutihkan, Thinify untuk membuat wajah jadi tirus, Make up jika ingin menambahkan perona pipi, lipstik atau 
eyeliner, dan seterusnya. Pengguna dapat memilih dan mengatur warna, bentuk, ukuran serta tebal tipisnya efek yang akan diaplikasikan, misalnya memilih bentuk dan warna eyeliner, memposisikan dan mengatur ukurannya sedemikian rupa agar pas menempel di foto bagian mata. Kemudahan dan banyaknya kemungkinan pilihan yang dialami oleh pengguna ketika ia berinteraksi dengan beauty apps memberikan kebebasan baginya untuk tampil cantik sesuai dengan idealismenya, tanpa mengeluarkan banyak biaya, waktu dan tenaga. Dibandingkan dengan perawatan di salon atau permak wajah, melakukan makeover digital juga cenderung aman, apabila seseorang tidak menyukai tampilan foto hasil suntingannya, ia dapat menghapusnya dan dengan cepat mengubah ulang tampilannya tanpa ada dampak apapun secara fisik. Makeover wajah dilakukan dalam hitungan detik, perempuan dapat berganti-ganti penampilan sesuka hati kapanpun dan di manapun. Tampilan wajah yang satu, lima menit kemudian akan berganti ke tampilan wajah berikutnya, secepat mata menatap. Oleh karenanya berinteraksi dengan beauty apps adalah sesuatu yang menyenangkan. Perempuan menjadi ketagihan untuk selalu melakukan makeover pada fotonya sebelum di unggah ke sosial media, semakin banyak yang melakukannya, hal tersebut menjadi suatu kebiasaan, suatu gaya hidup yang membudaya. Budaya yang digambarkan Piliang sebagai budaya yang berdasarkan kepada kesenangan, kesementaraan dan kecepatan menatap ${ }^{v}$.

\section{Kecantikan dengan beauty apps dan budaya makeover digital di kalangan perempuan}

Budaya makeover digital mengkonstruksi kecantikan ke dalam bentuk-bentuk representasi digital berupa foto diri atau selfie. Foto selfie yang tadinya sebagai indeks akan realitasnya berubah menjadi realitas baru setelah dimodifikasi sedemikian rupa oleh beauty apps. Dikarenakan kemudahan dan banyaknya kemungkinan pilihan dari beauty apps, foto selfie menjadi semacam versi diri yang ideal, yang lebih putih, lebih tirus, dan lebih cantik. Para perempuan kemudian berlomba-lomba untuk menjadi cantik yang paling ideal dari sudut pandangnya, sesuai dengan pembahasan Widjajanti tentang feminitas dalam tontonan. vi Kecantikan menjadi sebatas pemandangan, karena setiap perempuan asalkan dia punya smartphone dengan beauty apps, dia bisa menciptakan versi dirinya yang cantik dengan cepat dan mudah, sehingga cantik bukan lagi sesuatu yang bermakna. Perempuan tampil cantik demi kepuasan tontonan yang sementara. Foto saat ini, segera setelah disunting, diunggah dan dikomentari di media sosial akan tergantikan oleh foto berikutnya. Semakin cepat ia mengunggah fotonya maka hasrat kenikmatan visualnya terpenuhi. Hasrat yang berdasarkan pada kesenangan, kesementaraan dan kecepatan menatap. Berkaitan dengan pembahasan Widjajanti tentang feminitas dan male gaze vii, kenikmatan visual (voyeurisme) yang dirasakan perempuan ketika melihat foto selfie-nya, berbeda dengan hasrat seksual lelaki yang melihat perempuan sebagai obyek.

Mengacu pada hasil penelitian sebelumnya, budaya makeover digital seolaholah mengaktifasi female gaze, bukan hanya 
lelaki yang menonton tetapi perempuan juga ikut menonton viii. Perempuan diposisikan sejajar dengan laki-laki, perempuan menonton dirinya sendiri, perempuaan sebagai khalayak yang aktif menentukan tontonan. Aktifasi female gaze tersebut dijembatani oleh media seperti beauty apps. Media ini memiliki sifat seperti permainan interaktif dalam definisi kategori media baru Mc Quail, pengalaman perempuan dalam menggunakan beauty apps telah berubah menjadi interaktif, otonomi dan playful (kesenangan bermain). Menjadi pengalaman interaktif karena secara timbal balik ketika perempuan menginginkan kulit putih dengan menggeser bar di layar smartphone, ia mendapatkan respon balik dari sumber, yaitu tampilan di foto-kulit yang semakin cerah. Perempuan mendapatkan otonomi dalam melakukan konstruksi kecantikan, ia memiliki otonomi untuk menentukan bagaimana foto selfie-nya menjadi cantik. Interaksi tersebut menyerupai aktifitas bermain karena menyenangkan dan ringan ${ }^{\mathrm{ix}}$.
Pembahasan Ibrahim dan Akhmad yang mengacu pada uraian gagasan Ang tentang khalayak perempuan sebagai subyek aktif, mendeskripsikan posisi perempuan ketika berinteraksi dengan beauty apps bukan lagi sebagai korban pasif male gaze, melainkan menjadi subyek aktif yang menentukan apa yang terbaik bagi hidup mereka, termasuk untuk tujuan kesenangan semata. Ibrahim dan Akhmad juga merangkum gagasan Stuart yang sejalan dengan pemikiran Barthes dalam Piliang mengenai khalayak perempuan yang menjadi berdaya karena menegosiasikan dan melawan konsep patriarki dengan ikut menentukan, memutuskan, memodifikasi tubuh (bentuk rahang, warna kulit dan sebagainya) sebelum dipertontonkan $\mathrm{x}$. Sehingga kecantikan yang tercitra di foto diri merupakan sebuah konstruksi, hasil pengaturan dan modifikasi idealisme sosial kecantikan yang secara paradoks dilakukan oleh perempuan melalui beauty apps, juga sebaliknya oleh beauty apps yang terinspirasi oleh kecantikan perempuan Asia.
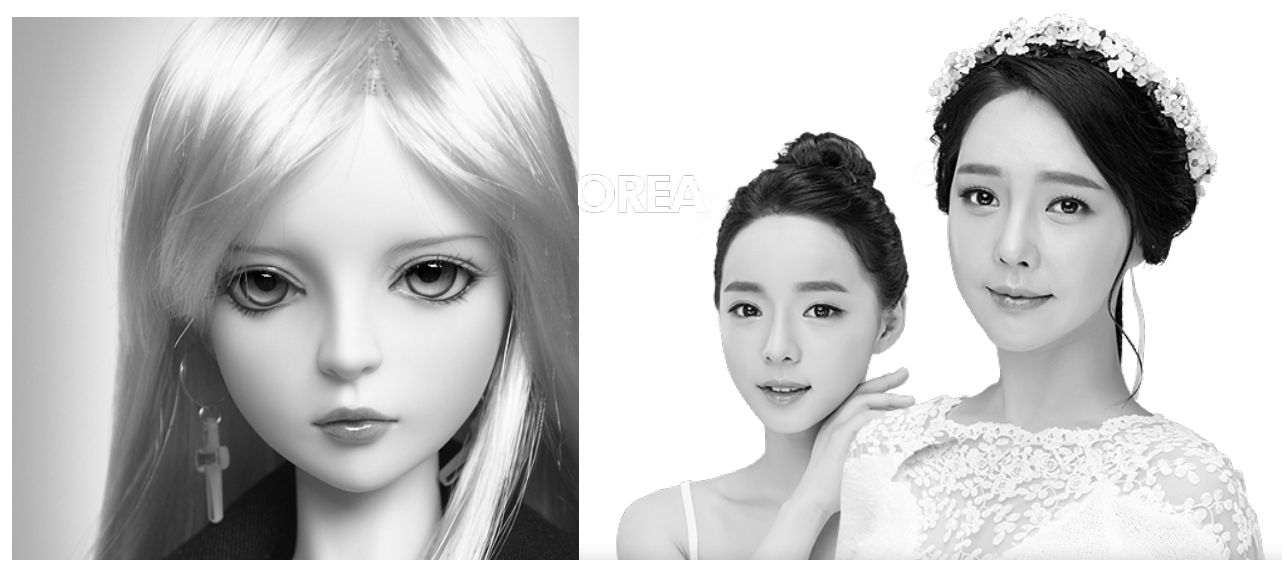

Gambar 3 Boneka Ball Joint koleksi Dream of Doll Korea (kiri). Sumber : http://www.dreamofdoll.com diunduh 26/06/2015 pkl. 15.32 .

Kecantikan Korea yang terinspirasi dengan BJD Doll dicirikan dengan mata besar bulat, alis mata lurus, wajah tirus, dagu mengecil dan dandanan yang terlihat alami (kanan).

Sumber: https://wonjinbeauty.wordpress.com/ diunduh 26/06/2015 pkl. 15.30 


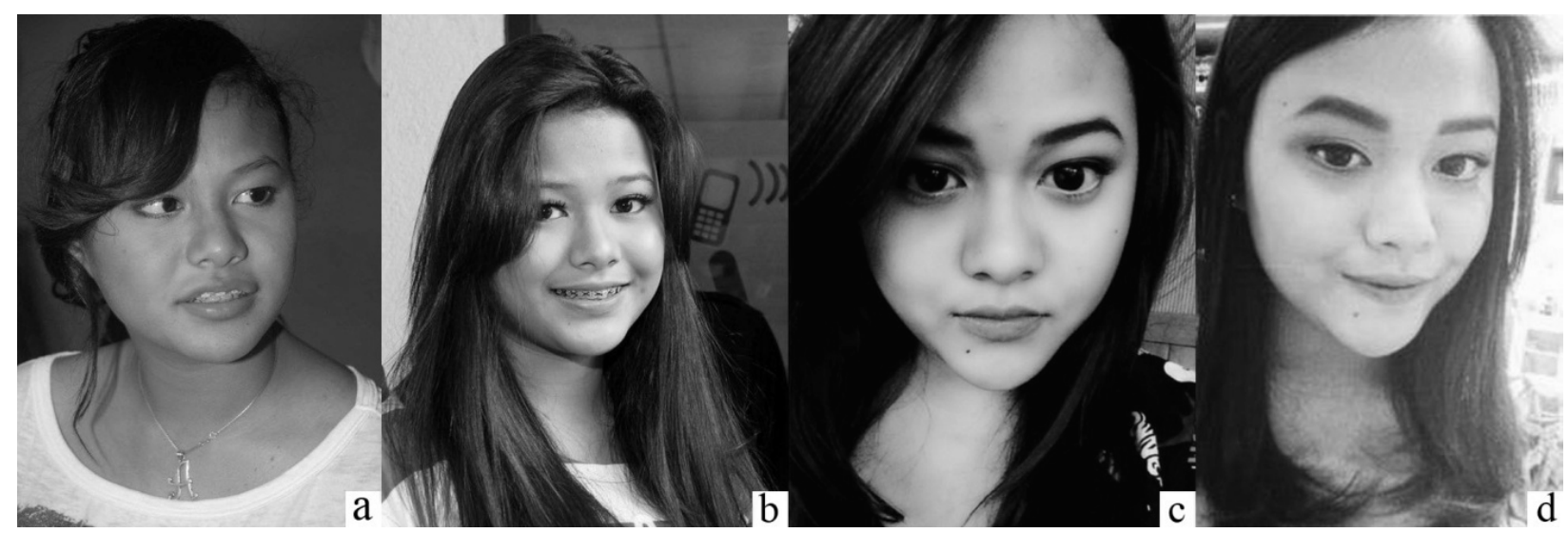

Gambar 4 Foto Aurel Hermansyah. Foto $\mathrm{c}$ dan d diedit dengan memutihkan dan menghaluskan kulit serta mengubah bentuk wajah menjadi lebih tirus. Foto $\mathrm{c}$ mata diperbesar, sedangkan foto d diberikan efek pencahayaan hangat. Sumber:http://www.kapanlagi.com/showbiz/selebriti/intip-perubahan-drastis-aurelhermansyah-amazing-90f39c-3.html diunduh 8 Mei 2015 pkl.11.51

Berdasarkan Studi kasus beauty apps camera 360 di penelitian sebelumnya dan uraian Slater yang mengutip pemikiran Jo Spence tentang perilaku konstruksi diri melalui pencitraan dalam bentuk foto. Slater menguraikan bahwa perilaku tersebut didasari oleh ritual evocation of social ideal atau kebiasaan menyuguhkan kepada khalayak apa yang ideal secara sosial, seseorang membatasi dan mengatur sedemikian rupa pencitraan dirinya di dalam foto $^{x i}$. Oleh sebab itu konstruksi kecantikan dengan tema dollface beauty diciptakan berdasarkan idealisme sosial di Asia. Perempuan dianggap cantik jika berkulit putih, bermata besar dan bermuka tirus seperti boneka. Idealisme tersebut disuguhkan melalui camera360 dalam bentuk efek-efek seperti Skin Smooth, Skin Tone and Whiten. Di Indonesia kaum selebriti dengan cerita kontroversi operasi plastiknya seperti Aurel Hermansyah ketika menggunakan aplikasi Camera 360 juga ikut memperkuat konstruksi sosial tersebut. Ternyata Aurel yang hanya melakukan makeover digital menghasilkan representasi diri dalam bentuk foto selfie yang tampak sangat berbeda dengan aslinya. Bagi khalayak perempuan foto selfie Aurel terlihat ideal; berkulit putih dan halus, bermata besar dan berwajah tirus seperti boneka. Mereka melihat bahwa untuk menjadi ideal seperti Aurel tidak perlu operasi plastik, bisa dilakukan dengan cepat, mudah, dan menyenangkan dengan Camera 360. Mereka juga melihat bahwa siapapun juga dapat menjadi cantik yang ideal. Akibatnya cara pandang mereka terhadap kecantikan berubah. Kecantikan bisa dibuat sedemikian rupa dan tidak mementingkan realitas yang ada secara fisik, semuanya hanya sebatas tontonan saja, bersifat kekinian dan segera. Cantik itu fun.

\section{Dampak dari budaya makeover digital pada perempuan dalam memaknai kecantikan dirinya}

Cara pandang terhadap kecantikan yang berubah akibat dari semakin mengakarnya budaya makeover digital, juga mengubah ritual di dalamnya. Sebelum adanya budaya tersebut, perempuan harus merencanakan waktu khusus, biaya serta tenaga untuk 
mempercantik diri. Perempuan harus pergi ke salon atau minimal masuk ke ruang ganti memakai make-up dan menyisir rambutnya supaya terlihat cantik sebelum di foto, sekarang hanya dengan menekan layar smartphone perempuan bisa langsung terlihat cantik di fotonya. Berdasarkan pembahasan Slater tentang praktek fotografi di budaya digital xii, dalam kasus beauty apps ini, jika sebelumnya perempuan mengambil dan menyunting foto selfie dengan smartphonenya hanya dilakukan di waktu luang karena dianggap bukan hal yang penting atau serius, sekarang menjadi semakin sering dilakukan. Sehingga ritual tersebut bukan lagi untuk mengisi waktu melainkan masuk menjadi sebuah gaya hidup, adalah suatu keharusan untuk menyunting setiap foto untuk terlihat cantik sebelum diunggah ke media sosial.

Menjadi cantik dengan cara yang fun dan interaktif semakin mendekatkan perempuan dengan beauty apps. Perempuan merayakan kecantikan yang banal atau tanpa makna yaitu sekedar tontonan mata bukan cantik secara nyata. Cantik bersifat segera dan rendah atau seperti yang dijelaskan Piliang dengan istilah $k$ itsch $^{\text {xiii }}$. Perempuan bisa mendapatkan kecantikan yang ideal tapi instan, seperti melakukan operasi plastik secara virtual. Kecantikan masing-masing individu yang berkarakter berganti dengan kecantikan hasil konstruksian secara sosial dengan campur tangan teknologi, seperti yang dijelaskan di atas. Tidak ada lagi foto selfie yang menampilkan kecantikan yang original dan singular, semuanya tampak sama dan mirip, meskipun semuanya bergantung pada selera masing-masing perempuan dalam menyunting fotonya. Setiap perempuan bisa memiliki selera yang berbeda-beda, namun tetap dibatasi oleh apps tersebut. Sesuai dengan deskripsi Piliang tentang imagologi dan gaya hidup, pada akhirnya perempuan menjadi terasing dari identitasnya, dari siapa dirinya ${ }^{\text {xiv }}$. Foto selfie yang diambil dan disunting dengan beauty apps adalah foto yang diatur sedemikian rupa seolah memiliki tema yaitu cantik dan ideal. Melalui Foto tersebut perempuan ingin ditonton seperti apa, orang lain menonton perempuan seperti apa, dan perempuan menonton dirinya sendiri seperti apa.

\section{KESIMPULAN}

Teknologi dalam budaya makeover digital menawarkan banyak kemungkinan yang mengaktivasi adanya female gaze. Sifatnya yang fun, interaktif, cepat dan instan mendorong timbulnya hasrat untuk selalu tampil cantik. Kecantikan yang didapatkan perempuan lewat beauty apps hanya sebatas voyeurisme atau kepuasan khayalan lewat representasi diri berupa foto. Dampaknya cara pandang dan ritual perempuan dalam memaknai kecantikan berubah, cantik tidak perlu secara nyata ada fisikalitasnya, cantik sebatas permukaan, fun, segera dan rendah atau kitsch. Perempuan menjadi teralienasi dari identitasnya sendiri, mereka memandang cantiknya berdasarkan konstruksi yang dibentuk oleh penonton, termasuk dirinya sendiri ikut mengkonstruksi ketika berinteraksi dengan teknologi beauty aps. Pada akhirnya foto yang seharusnya merepresentasikan realitasnya, menjadi realitas lain, bukan lagi image cantik dirinya, melainkan image cantik yang lain. Image cantik hasil konstruksi. 


\section{DAFTAR PUSTAKA}

[1] Ibrahim, I. S., \& Akhmad, B. A. (2014). Menjadikan Khalayak Perempuan Sebagai Subyek-Aktif. In I. S. Ibrahim, \& B. A. Akhmad, Komunikasi dan Komodifikasi Mengkaji Media dan Budaya dalam Dinamika Globalisasi (pp. 177-178). Jakarta: Yaaysan Pustaka Obor Indonesia.

[2] Lier, H. V. (2007). Extreme Art. In H. V. Lier, Philosophy of Photography Volume 6 of Lieven Gevaert (pp. 97102). Ithaca, NY: Cornell University Press.

[3] McQuail, D. (2014). Media Baru dan Komodifikasi Waktu Luang. In I. I. Subandy, \& B. A. Akhmad, Komunikasi dan Komodifikasi Mengkaji Media dan Budaya dalam Dinamika Globalisasi (p. 118). Jakarta: Yayasan Pustaka Obor Indonesia.

[4] Piliang, A. Y. (2010). Imagologi dan Gaya Hidup. In A. Y. Piliang, Dunia yang Dilipat Tamasya Melalui BatasBatas Kebudayaan (pp. 317-328). Bandung: Matahari.

[5] Piliang, Y. A. (2010). Libidosophy: Kapitalisme, Tubuh dan Pornografi. In Y. A. Piliang, Dunia yang Dilipat: Tamasya Melampaui Batas-batas Kebudayaan (pp. 291-299). Bandung: Matahari.

[6] Renaningtyas, L., \& Aniendya, A. (2015). Beauty Construction of Camera 360 apps in Indonesia. The $3 r d$ International Conference on Creative Industry. Bali: ICCI Indonesia.

[7] Santoso, W. M. (2011). Feminitas dalam Tontonan. In W. M. Santoso, Sosiologi Feminisme: Konstruksi Perempuan dalam Industri Media (pp. 50-57). Yogyakarta: Lkis.

[8] Slater, D. (1995). Domestic Photography and Digital Culture. In M. Lister, The Photographic Image in
Digital Culture (p. 134). London: Routledge.

\section{CATATAN AKHIR}

i (Renaningtyas \& Aniendya, 2015, hal. 94-98)

ii (Santoso, 2011, hal. 50-57)

iii (Piliang, 2010)

iv (Lier, 2007, hal. 97-102)

v (Piliang, 2010)

vi (Santoso, 2011, hal. 50-51)

vii (Santoso, 2011, hal. 52)

viii (Renaningtyas \& Aniendya, 2015, hal. 94-98)

ix (McQuail, 2014, hal. 118)

x (Ibrahim \& Akhmad, 2014, hal. 177-178)

xi (Slater, 1995, hal. 134)

xii (ibid)

xiii (Piliang, 2010, hal. 295)

xiv (Piliang, Imagologi dan Gaya Hidup, 2010, hal. 321) 